\title{
Educação na economia solidária: desafios e perspectivas
}

Education in social economy: challenges and perspectives

Telmo Adams*

Universidade do Vale do Rio dos Sinos

Resumo $\mathrm{O}$ artigo analisa os desafios e perspectivas de formação em economia solidária, tendo em vista o contexto de implementação de uma política pública nacional de educação. Após uma contextualização com foco na reestruturação produtiva do capitalismo e suas repercussões no mundo do trabalho, analisam-se potencialidades e limites sob o ponto de vista das reais mediações pedagógicas presentes nesses espaços de trabalho associado. Entre os desafios, destaca-se a atuação no campo das ideias, para reafirmar a centralidade do trabalho e discernir as características das alternativas da economia solidária em contraposição com a neoliberalização da solidariedade, bem como para afirmar uma prática social, ecológica, política e tecnológica que contribua para um novo modo de produzir e viver.

PALAVRAS-CHAVE: Educação, mediação pedagógica, economia solidária, trabalho associado.

Abstract The article analyzes the challenges and perspectives of education in social economy, considering the context of implementation of a national public policy in education. After situating the issue in the context of productive restructuring of capitalism, and its repercussions in the work world, there are analyzed the potentialities and limits under the perspective of real and potential pedagogical mediations found in these spaces of associated work. Among the challenges one can highlight the activity in the field of ideas to reaffirm the centrality of work, and the need to discern the characteristics of the alternatives in social economy in contrast to the neoliberalization of solidarity, as well as to affirm a coherent social, ecological, political and technological practice that contributes to a new mode of producing and living.

KEYWORDS: Education, mediation, social economy, associated work. 


\section{Introdução}

Multiplicam-se textos acadêmicos e outros que envolvem o tema da educação e economia solidária no atual estágio de institucionalização e implementação de políticas públicas estruturantes, especialmente no âmbito do governo federal e estados brasileiros. Os Centros de Formação em Economia Solidária, iniciados no ano de 2010, executaram, na primeira edição, um programa de educação de formadores com a perspectiva de consolidar uma dinâmica educativa multiplicadora. Para os mais de dois milhões de trabalhadores e trabalhadoras da economia solidária, identificados pelo primeiro mapeamento da Secretaria Nacional de Economia Solidária - Ministério do Trabalho e Emprego, o atual momento da política pública apresenta-se ainda na forma inicial, tanto na sua estruturação, quanto na destinação de recursos financeiros públicos.

Os programas educativos ora ensaiados, considerando as fragilidades dos mesmos, precisam ser compreendidos no contexto do processo de reestruturação produtiva em curso. Este é o objetivo inicial deste artigo: fazer uma contextualização das raízes históricas do atual momento e das perspectivas relacionadas às "metamorfoses do trabalho" (ANTUNES, 2009).

Num segundo momento, analisam-se as potencialidades e os limites da economia solidária como um dos movimentos de resistência e proposição dos trabalhadores e trabalhadoras, de âmbito local; e a seguir, o texto trata das possibilidades do trabalho associado como um lugar de produção e reprodução ampliada da vida e, como tal, um espaço de reais e potenciais mediações pedagógicas ${ }^{1}$ capazes de modificar o ethos individual e coletivo de trabalhadores e trabalhadoras. O sentido de ethos, utilizado neste artigo diz respeito à sabedoria implícita, à "memória de muitas tramas" (FREIRE, 1994, p. 32-33), adquirida ao longo de um itinerário de vida e que aos poucos vai imprimindo marcas, um conjunto de saberes, uma espécie de "matriz" de origem. Esta é portadora de saberes implícitos que fazem a mediação compreensiva das percepções e interpretações dos desafios cotidianos frente aos quais os sujeitos tomam posição, formulam seus julgamentos e definem sua ação. Ao constituir-se, simultaneamente, por um sistema de crenças, um modo de visão de mundo e modo de ser, o ethos individual permeia e se transforma no itinerário de formação de cada grupo social. Sob essa ótica, compreende-se o processo educativo como mudança do ethos que implica mudança compreensiva (conhecimento), nova postura (dimensão política) e novo agir (ação refletida) (ADAMS, 2010; GADOTTI, 2009).

Conclui-se com a indicação de desafios e perspectivas para a educação no campo da economia solidária, considerando que a dinâmica emancipadora exige que os trabalhadores e trabalhadoras rompam com uma cultura de dependência, elementos de subordinação incorporados ao ethos no decorrer da vida, em que os sujeitos se acostumaram a reproduzir relações de dominação, subserviência e dependência. 


\section{A reestruturação produtiva e as metamorfoses do trabalho}

A investida neoliberal, da década de 1970, desencadeou um processo de reestruturação capitalista de alcance mundial, dando um novo ritmo e cara à globalização dos mercados. A revolução na área das tecnologias e da comunicação e as profundas mudanças culturais repercutiram em todas as dimensões da vida.

O mundo do trabalho sofreu crescentes alterações sob o domínio de grandes corporações internacionais do capital financeiro especulativo (NOVAES, 2011), cuja ideologia dominante impôs seu predomínio em detrimento das necessidades dos trabalhadores e trabalhadoras, que permaneceram perplexos diante da flexibilização das relações de trabalho. Tal flexibilização exigiu, destas pessoas, que se tornassem trabalhadores e trabalhadoras capazes de adaptar-se às novas situações da reestruturação produtiva. A hegemonia taylorista-fordista havia gerado grandes avanços em termos de produtividade e acumulação de capital com o suporte de um Estado de Bem-Estar Social nos países do norte. Porém, esse modelo rígido, de produção de massa, hierarquicamente controlado, entrou em crise, e sua superação, com o alicerce das "novas" tecnologias de informação e comunicação, desenvolveu-se desde o "espírito do modelo japonês, o toyotismo, estabelecendo "uma relação dialética de ruptura e continuidade com o modelo anterior que não deixou de existir” (MORAES, 2011).

A queda do modelo socialista da União Soviética e da Alemanha Oriental foi o solo fértil para os enunciados da pós-modernidade, anunciando novos conceitos que foram se estabelecendo como uma monocultura, ao decretar o "fim da história", das classes e das alternativas ao capitalismo. Durante a década de 1990, o período foi de deslumbramento dos arautos do neoliberalismo e de perplexidade das organizações de trabalhadores e trabalhadoras e movimentos sociais. Os primeiros, sob o protagonismo dos países centrais, criaram consensos internacionais, não somente para a área econômica, mas também para a educacional. É o caso da UNESCO, com o seu relatório "Educação: um tesouro a descobrir" (1998), que direcionou direta ou indiretamente os sistemas de ensino da maioria dos países.

Já os críticos ao crescente fracasso do capitalismo na área produtiva ${ }^{2}$ e social, para não deixar morrer as utopias de um mundo com justiça social, buscaram encontrar novas estratégias para reconstruir propostas socialistas. Enquanto os países do norte articulavam-se no Fórum de Davos, as forças emancipadoras promoviam um movimento de mundialização das resistências e das experiências alternativas ao sistema hegemônico, reunindo organizações da maioria dos países, mesmo dos ricos. Além de denunciar o desemprego e a precarização do trabalho, o desmantelamento dos serviços públicos com sua vergonhosa privatização e mercantilização, tal mobilização tinha como objetivo básico mostrar as consequências do modelo predador de progresso ilimitado a qualquer preço e apontar para outras possibilidades de organização e relações socioambientais. O espaço referencial das lutas de antiglobalização capitalista a favor de outro mundo passou a ser o Fórum Social Mundial (AMIN; HOURTART, 2004).

Tais mobilizações ocorreram sob os fenômenos da crescente globalização (MEJÍA, 2007) ou mundialização, ${ }^{3}$ uma realidade complexa, constituída de múltiplos 
elementos interligados e que não pode ser compreendida no singular, sob risco de conduzir à aceitação passiva da ideologia do modelo hegemônico do capitalismo ocidental, "como se fosse a única forma de ocupar o tempo-espaço de hoje" (MEJÍA, 2007, p. 23). Dentro de diversos entendimentos de globalização, a perspectiva crítica vê esse processo, prioritariamente, como intervenção ideológica e prática do capitalismo contemporâneo, constituindo-se em uma nova fase de imperialismo que se caracteriza pela concentração e centralização (MORAES, 2011). O resultado é uma reconfiguração das dependências, gerando novas periferias com trabalhadores e trabalhadoras em processo de empobrecimento e, muitas vezes, sem perspectivas de emprego ou trabalho digno, inclusive no interior dos países dominantes. Como a mundialização dos mercados voltados para a maximização do consumo incide sobre as metamorfoses do trabalho, especificamente desde a década de 1990, quando se deram profundas transformações nas relações mundiais, no mercado financeiro e no interior das empresas?

A despersonalização e desterritorialização da propriedade das grandes empresas no modelo toyotista enveredou pela pulverização de suas ações, cujos acionistas são movidos pela obtenção do máximo lucro. "Ocorre um processo de financeirização da gestão das empresas. Entretanto, a meta principal é a mesma da empresa fordista: acumular capital pela extração de mais-valia” (MORAES, 2011, p. 56). Mesmo que tais empresas assumam e estimulem seus acionistas pela valorização do meio ambiente, pela não utilização do trabalho infantil ou trabalho escravo, quem mais sofre as consequências decorrentes das estratégias de máxima lucratividade são os trabalhadores. Exemplos disso são as diferenciações nos contratos, estimulando o individualismo e a competição; a subcontratação de empresas e a consequente generalização da terceirização, atingindo, inclusive, os trabalhadores e trabalhadoras mais qualificados pela pressão produtiva através de contratos por tarefa, de caráter temporário, sem garantias sociais e sem ônus para a empresa. A chamada flexibilidade é, na verdade, a fluidez do trabalho resultante do desmantelamento da solidariedade de classe pelo capital, gerando um "estranhamento do trabalhador com relação ao seu trabalho e com relação aos demais trabalhadores" (MORAES, 2011, p. 58).

Tendo presente a configuração de uma "nova morfologia do trabalho" (ANTUNES, 2005; 2009), - e diante da impossibilidade de que o capital, mesmo sob a forma de capital monetário, exista sem o trabalho (RUMMERT et al, 2013) - a atual fase da reestruturação produtiva "agrega as variações de precarização capazes de reduzir, ainda mais, os custos do trabalho [...]". As autoras citam como exemplo: "o emprendedorismo, o cooperativismo induzido, a terceirização e a quarteirização, a subcontratação, o trabalho domiciliar, ou seja, as diferentes estratégias de expropriação dos direitos do trabalho" (RUMMERT et al, 2013, p. 719). No modo de produção capitalista, em última análise, seja qual for a forma de relação entre capital e trabalho, é este último que remunera o primeiro, inclusive o capital monetário.

\section{O alcance das resistências e das alternativas locais de traba- Iho associado}

Em âmbito local, em que pese a mundialização capitalista, multiplicamse formas de resistência com (re)criação de espaços coletivos, que buscam fortalecer 
atores e projetos emancipadores desde as "margens" (TORRES, 2006). Os empreendimentos de trabalho associado que integram a economia solidária, para além da resistência - apesar da fragilidade e contradições inerentes a eles -, pretendem cultivar um espaço real de trabalho emancipado: associado, autogestionário, mais autônomo e de caráter não alienado ${ }^{4} \mathrm{O}$ trabalho emancipado apregoado na economia solidária propõe-se a um

novo sentido do trabalho que tem como horizonte a constituição de uma nova sociedade, na qual o trabalhador supere sua condição de mercadoria, resgate o direito de ser proprietário coletivo dos meios de vida, consiga superar a desvinculação entre si e seu produto, controlando o ritmo e o tempo de trabalho. (TIRIBA, 2001, p. 90)

A utopia inspiradora dessas experiências aponta para outros modos de compreensão, outro padrão tecnológico com a utilização e geração de tecnologias sociais e outra visão de desenvolvimento (SINGER, 2004).

É possível que a economia solidária esteja se constituindo como uma das tendências de organização dos trabalhadores, decorrente das atuais transformações no mundo do trabalho no contexto, especificamente em uma das características centrais que é a ampliação da flexibilidade da legislação trabalhista, da terceirização e precarização do emprego. O fenômeno da informalidade, visto por alguns teóricos como uma face do advento de uma sociedade pós-capitalista sem trabalho, na verdade, tende a tornar-se a forma dominante de trabalho precarizado na produção e reprodução do capital. Grande parte da economia solidária ainda não formalizada integra esse mundo econômico que, segundo estimativas, é superior a $50 \%$ da população brasileira economicamente ativa (DAGNINO, 2012). E como tal, os empreendimentos solidários não são isentos de reproduzir as formas precarizadas de trabalho proporcionadas nesse campo da economia onde

proliferam cooperativas, empresas familiares, trabalho domiciliar, micro e pequenas empresas [...] A flexibilidade invade a organização da produção, fragmentando e desqualificando o trabalho, promovendo o desemprego e a reemergência de velhas formas de trabalho precarizado. [...] (TAVARES, 2004, p. 18)

Nesse espaço contraditório, é preciso situar o modo solidário de produzir. O trabalho associado dentro dos princípios de autogestão, em última análise, permanece como um processo marginal, inserido e dependente do modo de produção capitalista dominante. Isso fica mais evidente quando uma cooperativa é contratada por uma empresa privada ou pública com o objetivo de diminuir custos, o que significa, em geral, uma maior exploração dos trabalhadores e trabalhadoras cooperativados. Além disso, trata-se de uma relação de extrema dependência da cooperativa frente às normas e condições que ela assume por meio de contrato ou convênio.

No entanto, essas limitações na autonomia da economia solidária, no contexto da economia dominante, não negam os significados reais para seus participantes, sua contribuição educadora e estratégica para experienciar outra cultura de trabalho e reascender utopias de outro mundo possivel. Trata-se de compreender que da contri- 
buição das cooperativas na desmercantilização da força de trabalho (NOVAES, 2011) não decorre automaticamente a consolidação de mudanças ao nível estrutural; mas, ao mesmo tempo, a mudança estrutural não acontece sem uma nova concepção e forma de organização do trabalho que se constrói na práxis local, isto é, numa ação intencional e criticamente refletida. A construção de uma cultura do trabalho associado assume as contradições, constituindo-se em mediação entre a antiga forma e o novo modo de produzir, a partir de uma compreensão dialética (TIRIBA, 2006). De acordo com Novaes (2011), os pensadores clássicos concluíram que o cooperativismo e outras experiências de auto-organização dos trabalhadores carregam um potencial de transformação social, com perspectiva de transcender o trabalho alienado. Segundo o autor, "as cooperativas de resistência são 'anfíbios embrionários' que poderão florescer ou degenerar, em função do processo histórico no qual estão inseridos" (NOVAES, p. 162). E poderíamos acrescentar que isso depende, igualmente, da capacidade de organização orgânica e articulação das forças emancipadoras que intencionam um outro desenvolvimento que contemple os interesses da classe trabalhadora.

\section{Trabalho associado: um espaço de educação e reprodução ampliada da vida ${ }^{5}$}

Historicamente, mais que hoje, era pelo trabalho que, em grande parte, o ser humano construía sua identidade social e profissional. Contudo, cada vez mais, em função das mudanças ocorridas na sociedade contemporânea, outros elementos começaram a fazer parte das mediações formadoras das identidades dos trabalhadores e trabalhadoras. A educação realiza-se sempre por meio de múltiplas mediações encharcadas pela dimensão material da vida, de modo especial, pela experiência do trabalho. De acordo com a acepção marxiana, o trabalho humano congrega toda a atividade produtiva e criativa de bens materiais e imateriais, produzindo, assim, o mundo, o próprio ser humano: a cultura. Ou seja, a ação humana transformadora da natureza resulta no mundo da cultura que, por sua vez, exerce um efeito recíproco de (des)humanização do próprio ser humano - sujeito do trabalho. Nessa concepção, o trabalho não se restringe à ação produtora de mercadorias, mas abrange o "sentido mais amplo de toda ação criadora ou transformadora, que relaciona uma pessoa ou um grupo social consigo próprio, com outros e/ou com a natureza" (ARRUDA, 2003, p. 204). Pela atividade humana do trabalho, o ser humano se insere na experiência de participação ativa como sujeito social.

Assim sendo, mesmo na forma capitalista, onde o trabalho se reduz a fator de produção em troca de um salário - que significa, para a grande maioria, uma precária condição de sobrevivência -, sempre existe algum tipo de associatividade. E vale considerar que nenhuma economia torna-se solidária só porque as pessoas são boas e generosas ou porque acreditam no trabalho solidário como projeto político. $\mathrm{Na}$ perspectiva dialética, em que pese o contexto adverso que induz à alienação, os trabalhadores e trabalhadoras podem desenvolver processos de formação emancipadores na atividade cotidiana do trabalho. Tal prática depende, entre outros fatores estruturais, da capacidade de compreensão, organização e gestão do trabalho, além da desenvoltura profissional dos sujeitos envolvidos e do processo reflexivo presente nos coletivos de trabalho, estimulados ou não por educadores(as) externos aos empreendimentos. 
Entretanto, potencialmente, no processo de trabalho associado, o ambiente propício favorece a formação de uma cultura do trabalho. A designação "trabalho associado" pressupõe um conjunto de ações de caráter associativo e solidário, uma organização intencional que se propõe a empreender dentro das concepções e sentidos da autogestão (ADAMS, 2010). A finalidade de empreendimentos de trabalho associado é, em primeiro lugar, a cooperação em vista da satisfação das necessidades humanas fundamentais, onde os(as) participantes exercem a liberdade e autonomia possível na criação e recriação de um mundo do trabalho, com relações sociais de convivência solidárias. As forças individuais são postas em comum e permanecem sob a gestão, o controle e apropriação dos resultados de forma participativa e comum.

Trata-se da proposição de um cooperativismo popular em que os trabalhadores e trabalhadoras cultivam pelo menos três dimensões de participação igualitária e corresponsável: na propriedade, na gestão e nos resultados. Juntam-se a isso as relações solidárias de cultivo de uma convivência respeitosa, de valorização mútua e uma atitude cuidadosa na relação com o socioambiente.

Distintamente da forma de trabalho capitalista, os(as) trabalhadores(as) associados(as) articulam estrategicamente os fatores do trabalho e da solidariedade para que estes deem a direção aos demais fatores de produção, dentro dos limites da lógica do mercado hegemônico. A finalidade mobilizadora é a partilha equitativa dos resultados do trabalho para o bem-viver. (ADAMS, 2010, p. 52)

Como espaço de relações educativas, o trabalho associado pode atingir variadas dimensões da vida. O ponto de partida é o antigo padrão incorporado (ethos de origem, em geral a experiência capitalista de trabalho) juntamente com algum nível de produção social (criação do novo - formação de um novo ethos). Como diz Martins (2000, p. 63): "Não há repetição do velho sem certa criação do novo". Nesta linha, o trabalho associado favorece a intervenção dos coletivos de trabalho como sujeitos do processo produtivo. Em decorrência, é possível afirmar que o trabalho associado apresenta um potencial emancipador, na medida em que se constitui um espaço para a prática de novas relações sociais de produção, visando a obtenção de resultados econômicos e a satisfação de suas necessidades e desejos comuns de uma vida mais feliz. Estes são elementos de um projeto ético-político, uma utopia em cuja direção já se deram alguns passos, mas será uma permanente construção.

Acreditar numa contribuição emancipadora da educação implica assumir que as condutas de vida são aprendidas em um ambiente. Todos os ambientes oferecem a capacidade de educar, dependendo da nossa percepção e relação significativa com eles. "Um ambiente educativo será um lugar de encontro que possibilita a criação permanente de novas situações, nas quais o 'eu' e o 'nós' estão em relação recíproca, dinâmica e construtiva" (GUTIÉRREZ, 1999, p. 113). O trabalho associado oportuniza, de modo especial, esse fluxo de relações que germinam e frutificam processos econômico-educativos, capazes de alterar o ethos individual e coletivo. Na prática, "a subjetividade do trabalhador não é só o resultado das relações vividas no ambiente de trabalho, mas constrói-se e se reconstrói a partir das diferentes experiências vividas em diferentes microprocessos e redes complexas [...] (TIRIBA, 2001, p. 236)”. Ou 
seja, a singularidade das motivações e interesses dos sujeitos não é somente produto determinado pelas condições objetivas tampouco é pura construção voluntarista. Ela se constitui na dialética das relações sociais que se estabelecem em qualquer atividade humana, mas, de modo especial, nas relações de trabalho.

Arroyo (1997, p. 66) argumenta que: "Somos seres humanos colados a um espaço que é o espaço do trabalho, o espaço familiar que deve ser o berço, a matriz de nossa educação e formação". Nestes termos, o agir condicionado por um longo itinerário de vida tende a moldar um estilo de conduta. Um longo tempo de vida sob um ambiente de competição, onde se cultivam valores de expropriação, dominação, animosidade etc., consolida comportamentos duráveis, cuja herança se torna matriz condicionante do agir dos indivíduos e grupos sociais. Aqui não se trata de um tempo no sentido linear, pois entram múltiplos componentes que oportunizam um ambiente de rupturas, favoráveis ou desfavoráveis ao processo de novos aprendizados e mudanças de posturas, comportamentos e práticas. Estas dependem das condições subjetivas na relação com as objetivas. Frente a isso, o trabalho associado pode constituir-se um ambiente adequado para resistir à cultura de competição e individualismo. Com base em interesses e elementos de identidade comuns, uma organização autogestionária de trabalhadores e trabalhadoras pode constituir um ethos coletivo de referência, que estabelece certo tipo de interação com as condições objetivas do contexto conjuntural e estrutural em que se encontram os referidos sujeitos. Em consequência, as reais e potenciais mediações pedagógicas presentes nesses espaços, podem gerar relações sociais de produção solidárias para alcançar melhores condições de trabalho, e estas propiciarão uma vida de qualidade superior em termos de humanização e dignidade.

$\mathrm{Na}$ pesquisa desenvolvida com cooperativas de recicladores, ${ }^{6}$ os participantes enfatizaram os aprendizados na atividade coletiva de trabalho oportunizadas nesse espaço, indicando o desafio da formação para o trabalho autogestionário (NASCIMENTO, 2011). A problematização da prática alienadora do trabalhador empregado e dependente, ao passar por momentos conflitivos e, por vezes, de muito sofrimento, medo e insegurança, lentamente gerava novas compreensões, posturas e atitudes. Passar de uma visão instrumental e utilitarista do trabalho para assumir um novo paradigma de outro modo de produzir - ao combinar viabilidade econômica com a participação na construção de uma sociedade diferente da concepção de desenvolvimento, identificado como crescimento ilimitado ou exploração da natureza e do trabalho humano - sintetiza o grande desafio de construção de um ethos favorável ao processo de emancipação individual e social.

\section{Reflexões não conclusivas}

Nesse caminho, em meio a ambiguidades e ambivalências intrínsecas ao processo, trabalhadores associados juntamente com educadores, estes, em geral, referenciados a entidades de apoio, perseguem a ousada meta de educar para uma nova cultura do trabalho (TIRIBA, 2004), na práxis cotidiana desta atividade no campo da economia solidária, potencializada por processos formativos específicos devidamente preparados. O desafio é atingir e melhorar as condições objetivas e ético-políticas relacionadas a um resultado econômico, que garanta uma vida digna aos participantes e, ao 
mesmo tempo, modifique o ethos individual e coletivo dos participantes, para formar sujeitos coletivos capazes de escolher e lutar por um projeto de emancipação social.

Nessa visão, ao assumir a economia solidária como espaço educativo, necessita-se romper com estigmas, como, por exemplo, vê-la como um lugar de refúgio dos desempregados, ou como espaço de políticas sociais compensatórias. Esses empreendimentos "carregam os germes de um novo sentido para o trabalho, de um novo projeto de desenvolvimento econômico" (TIRIBA, 2006, p. 67). Porém, como essa potencialidade emancipadora é reconhecida pelos sujeitos da economia solidária? A superação do trabalho alienado pela autogestão dos trabalhadores implica a compreensão de novos sentidos do trabalho, articulados à perspectiva de outro projeto de economia e sociedade que, para se viabilizarem, necessitam de um processo educativo coerente, com princípios e valores da educação popular, ressignificando sua longa tradição na experiência latino-americana.

Educadores têm uma contribuição importante no sentido de suscitar mediações pedagógicas em vista de fortalecer sujeitos econômicos de empreendimentos solidários, não somente produtores de bens, mas partícipes do movimento mais amplo da sociedade que busca reverter o quadro de desigualdade, concentração de renda e que gera uma massa de seres infra-humanos condenados a viver das migalhas do consumismo. (ADAMS, 2010, p. 184)

No contexto contraditório é necessário, pois, compreender que a economia solidária constitui-se de espaços prenhes de elementos reais e potenciais, simbólicos e materiais valiosos, com potencial educativo emancipador, de alguma forma condicionados ao sistema do mercado dominante, já caracterizado na parte inicial deste artigo. A produção e reprodução de mecanismos de dominação, exploração e de exclusão atingem indivíduos e organizações onde as de economia solidária não estão isentas de influências (CATANI, 2003). Como evitar que essas iniciativas acabem corroídas na sua dimensão revolucionária ou capitalizadas como formas de precarização do trabalho? Daí a necessidade de fazer frente a três níveis de desafios (CATANI, 2003): a) a disputa no campo das ideias, reafirmando a centralidade do trabalho na atual sociedade compreendendo-o como princípio educativo; b) discernir com clareza as características das alternativas da economia solidária e das práticas desenvolvidas pelo ambíguo e ambivalente "terceiro setor" (ADAMS, 2010), que se constitui, em última análise, um processo de "neoliberalização da solidariedade" (DOCKENDORFF, 2010); c) um terceiro, que tem a ver com uma prática social, ecológica, política e tecnológica que supere o padrão capitalista de mercantilização de tudo o que existe.

É imprescindível superar uma visão dualista que transpareça nas experiências de formação em economia solidária. Ou seja, de um lado, sujeitos de empreendimentos que entendem o processo de formação como integração, troca de experiência e aprendizado técnico voltado à qualificação da gestão, produção, comercialização, crédito, entre outros; e de outro, boa parte das entidades de apoio à economia solidária, assumindo, prioritariamente, a formação voltada à compreensão dos princípios e questões relacionadas com o projeto ético-político. Ao nosso ver, não cabe essa postura de cunho dicotômico e até maniqueísta, em que o conteúdo doutrinal-ideológico 
torna-se sinônimo de algo bom, e o interesse de trabalhadores associados em aprender a qualificar a produção para "vender mais", por exemplo, é encarado como alienação, como se fosse algo dissociado das finalidades da economia solidária. Ora, a geração de resultados econômicos é da sua essência, sendo que as dimensões técnico-produtiva e ético-política (ideológica) podem e devem ser parte da mesma construção da chamada "outra economia". Aponta-se, nesse sentido, que a dimensão econômica, agregada à metodologia da educação popular, pode potencializar-se ao estabelecer uma interação com o saber já sistematizado, facilitando a busca conjunta na geração de novos modos de organização e realização do trabalho com práticas criativas, que se tornem mediações para a constituição de um ethos solidário, terno e democrático (ADAMS, 2010).

Finalmente, vale dizer que uma educação que se restringisse a criar um clima de solidariedade no interior do empreendimento seria uma prática descontextualizada. A presença da solidariedade em práticas sociais não garante um processo de emancipação social. A dinâmica emancipadora exige que os trabalhadores e trabalhadoras rompam com uma cultura de dependência, elementos de subordinação incorporados ao ethos no decorrer da vida, em que os sujeitos se acostumaram a reproduzir relações de dominação, recebendo ordens. Trata-se de um longo caminho para a autonomia a fim de superar o padrão entranhado desde os processos educativos ocorridos na família, na escola e nas relações sociais, no trabalho e na vida cotidiana. Nos empreendimentos solidários, pela atividade do trabalho, com seus múltiplos elementos - seja pela sua organização, prática de gestão, relações de trabalho e convívio ou relações com espaços externos; seja pelo uso de objetos técnicos, saberes partilhados e construídos, etc. -, podem constituir-se em mediações para (re)construir um novo ethos do cuidado e consolidar uma cultura do trabalho associado. Articulando a vida dos empreendimentos solidários com o envolvimento e participação em lutas emancipatórias mais amplas, os trabalhadores e trabalhadoras organizados podem sacudir a carga alienante que pesa sobre sua cultura, irmanando-se com os iguais para trilharem os caminhos da autogestão e da emancipação social.

\section{Referências}

ADAMS, T. Educação e economia popular solidária: mediações pedagógicas do trabalho associado. Aparecida: Idéias \& Letras, 2010.

ARROYO, M. Pedagogia das relações de trabalho. Trabalho \& Educação: Revista do NETE, n. 2, p. 61-67, ago./dez. 1997.

AMIN, S.; HOURTART, F. (editores). Mundialización de lãs resistências. Estado de lãs luchas 2004. Colômbia: Ediciones Desde Abajo, 2004.

ANTUNES, R. Século XXI: nova era da precarização estrutural do trabalho? In: ; BRAGA, R. (Orgs.). Infoproletários: degradação real do trabalho virtual. São Paulo: Boitempo, 2009. p. 231-238.

; BRAGA, R. (Orgs.). Infoproletários: degradação real do trabalho virtual. São Paulo: Boitempo, 2009.

ARRUDA, M. Humanizar o infra-humano: a formação do ser humano integral: homo evolutivo, práxis e economia solidária. Petrópolis: Vozes, 2003.

CATTANI, A. (Org.). A outra economia. Porto Alegre: Veraz, 2003. 
DAGNINO, R. Parâmetros para a construção de indicadores. In: KRAYCHETE, G.; CARVALHO, P. Economia popular solidária: indicadores para a sustentabilidade. Porto Alegre: Tomo; Salvador: UCSAL, 2012. p. 55-72.

DOCKENDORFF, C. et al. La Neoliberalización de la solidaridad en el Chile Democrático. Una mirada comparativa sobre discursos solidarios en 1991 y 2006. Latin American Research Review. Santiago, v. 45, n. 1, p. 189-202, 2010. Disponível em: <http://lasa-4.univ.pitt.edu/ LARR/prot/fulltext/Vol45no1/Dock-Brug-Spro_189-202_45-1.pdf>. Acesso em: 10 set. 2012.

FREIRE, P. Pedagogia da esperança: Um reencontro com a Pedagogia do Oprimido. 3. ed. São Paulo: Paz e Terra, 1994.

GADOTTI, M. Economia solidária como práxis pedagógica. São Paulo: Instituto Paulo Freire, 2009 (Série Educação Popular, 1).

MARTINS, J. S. A sociabilidade do homem simples: cotidiano e história na modernidade anômala. São Paulo: Hucitec, 2000.

MEJÍA J., M. R. Educación(es) en la(s) globalización(es): entre el pensamiento único y la nueva crítica. Bogotá: Ediciones desde Abajo. 2007.

MORAES, L. C. G. Mundialização do capital e as novas formas de imbricação entre as dimensões financeira e produtiva. In: BATISTA, E. L.; NOVAES, H. (Orgs.). Trabalho, educação e reprodução social. As contradições do capital no século XXI, 2011. p. 41-62.

NASCIMENTO, C. Experimentação/autogestionária: autogestão da pedagogia/ pedagogia da autogestão. In: BATISTA, E. L.; NOVAES, H. (Orgs.). Trabalho, educação e reprodução social. As contradições do capital no século XXI, 2011. p. 107-132.

NOVAES, H. T. A autogestão como magnífica escola: notas sobre educação no trabalho associado. In: BATISTA, E. L.; NOVAES, H. (Orgs.). Trabalho, educação e reprodução social. As contradições do capital no século XXI, 2011.p. 133-178.

RUMMERT, S. M.; ALGEBAILE, E.; VENTURA, J. Educação da classe trabalhadora brasileira: expresssão do desenvolvimento desigual e combinado. Revista Brasileira de Educação, v. 18, n. 54, p. 717-738, jul./set. 2013.

SINGER, P. Desenvolvimento capitalista e desenvolvimento solidário. (Estudos Avançados, 18) (51), 2004. Disponível em: <http://www.scielo.br/pdf/ea/v18n51/a01v1851.pdf>. Acesso em: 3 mar. 2012.

TAVARES, M. A. Os fios (in)visíveis da produção capitalista: informalidade e precarização do trabalho. São Paulo: Cortez, 2004.

TIRIBA, L. Economia popular e cultura do trabalho: pedagogia(s) da produção associada. Ijuí, RS: Editora Unijuí, 2001 (Coleção Fronteiras da Educação).

Ciência econômica e saber popular: Reivindicar o "popular" na economia e na educação. In: PICANÇO, I.; . (Orgs.). Trabalho e educação: arquitetos, abelhas e outros tecelões da economia popular solidária. Aparecida: Ideias \& Letras, 2004. p. 75-101.

TIRIBA, L. Economia popular e cultura do trabalho. IHU Online. São Leopoldo: n. 173, p. 65-67, 17 mar. 2006.

TORRES C., A. Por una investigatión desde el margen. In: ; JIMÉNEZ B., A. (Orgs.). La práctica investigativa en ciências sociales. Bogotá: Fondo Editorial Universidad Pedagógica Nacional, 2006. p. 61-79. 


\section{Telmo Adams}

\section{Notas}

${ }^{1}$ Todas as relações sociais, de interação ou conflito, provocadas tanto por dimensões objetivas como subjetivas, espontâneas ou intencionais, quer do mundo da produção material ou das relações interpessoais e intergrupais, oportunizam, de alguma forma, mediações pedagógicas.

${ }^{2}$ Frente às crescentes crises e na ânsia de manutenção do lucro, desenvolveu-se o capitalismo financeiro que hoje prevalece sobre o capital produtivo onde "as privatizações, aberturas comerciais e desregulações formam um tripé basilar na nova função do Estado, de servidor do mercado, principalmente, do mercado financeiro" (MORAES, 2011, p. 46). No mesmo livro, o artigo de Henrique T. Novaes (p. 133-178) enfatiza a importância de, nas análises, não relativizarmos as implicações que ocorrem entre o capital financeiro e a reestruturação produtiva.

${ }^{3}$ Segundo alguns autores como Raúl Mejía (2007), Boaventura de Sousa Santos (2004), dever-se-ia utilizar o termo globalização no plural: globalizações. Os conceitos de globalização e mundialização devem ser distinguidos pelo viés ideológico. Enquanto o termo global passou a ser utilizado pelos grandes grupos econômicos para reivindicar um mundo sem fronteiras para o capital, "o termo mundialização aparece para melhor conceituar este movimento, dando maior nitidez ao processo, e elucidando suas contradições internas" (MORAES, 2011, p. 47).

${ }^{4}$ De acordo com a compreensão marxista, duas dimensões distintas articulam o trabalho como mundo da liberdade (trabalho criador, emancipado, autogestionário) e mundo da necessidade (trabalho alienado, precarizado) (cf. FRIGOTTO, 2002).

${ }^{5}$ A reprodução ampliada da vida, e não do capital, estabelece uma integração entre o mundo da produção e o da reprodução. $\mathrm{O}$ entrelaçamento entre essas duas esferas da vida constitui-se em questão-chave na proposta da economia solidária. A reprodução ampliada da vida refere-se a um sentido mais amplo do que a reprodução biológica ou da sobrevivência (ADAMS, 2010).

${ }^{6}$ Pesquisa publicada no livro: Educação e economia popular solidária: mediações pedagógicas do trabalho associado. Aparecida, SP: Idéias \& Letras, 2010.

* Professor Doutor da Universidade do Vale do Rio dos Sinos, Canoas, Rio Grande do Sul - Brasil.

\section{Correspondência}

Telmo Adams - Universidade do Vale do Rio dos Sinos, Programa de Pós-Graduação em Educação. Av. Unisinos, 950, Cristo Rei - 92310-080 - Canoas, Rio Grande do Sul - Brasil.

E-mail: adams.telmo@gmail.com

Recebido em 14 de maio de 2014

Aprovado em 09 de julho de 2014 